\title{
Marfan syndrome: clinical consequences resulting from a medicolegal autopsy of a case of sudden death due to aortic rupture
}

\author{
M. Klintschar • U. Bilkenroth • M. Arslan-Kirchner • \\ J. Schmidtke • D. Stiller
}

Received: 17 June 2008 / Accepted: 8 September 2008 / Published online: 17 October 2008

(C) The Author(s) 2008. This article is published with open access at Springerlink.com

\begin{abstract}
To investigate the sudden death of a 31-year-old man, a medicolegal autopsy was performed. Major findings were a dilated aortic root with a longitudinal rupture of the intima and dissection of aorta and right coronary artery and consequent tamponade of the pericardial sac. Moreover, arachnodactyly and other skeletal deformities in combination with the histological finding of a pseudocystic medionecrosis of the aortic wall were noted. By sequencing of the FBN1 gene, a mutation $(1622 \mathrm{G}>\mathrm{A})$ leading to the diagnosis of Marfan syndrome was found. Genetic counseling was recommended to the relatives who reported that the father of the deceased had died at the same age from aortic rupture. While fortunately the child of the deceased lacked this mutation, it was found in his younger sister. The results of the autopsy thus enabled early diagnosis and beginning of treatment in the sister and thus a considerable statistical increase in lifespan. With this report, we want to show that
\end{abstract}

\author{
M. Klintschar $(\bowtie)$ \\ Department of Legal Medicine, Universitätsmedizin Göttingen, \\ Robert-Koch-Str. 40, \\ 37075 Göttingen, Germany \\ e-mail: Michael.klintschar@med.uni-goettingen.de \\ U. Bilkenroth \\ Institute of Pathology Eisleben, \\ Hohetorstr. 25, \\ 06295 Lutherstadt Eisleben, Germany \\ M. Arslan-Kirchner $\cdot$ J. Schmidtke \\ Department of Human Genetics, Medical University Hannover, \\ Carl-Neuberg-Strasse 1, \\ 30625 Hannover, Germany \\ D. Stiller \\ Department of Legal Medicine, \\ Martin Luther University Halle-Wittenberg, \\ Franzosenweg 1, \\ 06112 Halle (Saale), Germany
}

medicolegal autopsies can also have medical consequences for relatives. We argue that in all sudden and unexpected deaths in young persons up to 35 years an autopsy should be performed, not only to detect unnatural causes of death but also to identify heritable diseases and thus aid the relatives.

Keywords Marfan syndrome - Aortic aneurysm . Fibrillin-1 gene $\cdot$ Arachnodactyly $\cdot$ Early diagnosis

\section{Introduction}

As in most countries, the purpose of a medicolegal autopsy under the German code of criminal procedure is to identify and classify unnatural deaths and to establish facts for further inferences. In the last decades, in most parts of Europe, the attorneys have increased the threshold for having a medicolegal autopsy performed, and the autopsy rates have decreased [1]. We want to show in this report that a medicolegal autopsy might not only be essential for the recognition and correct investigation of felonies but can also identify a genetic disorder and thus help affected relatives. For these, early diagnosis would be especially important, as the treatment options of many genetically determined diseases have improved in the last years.

Marfan syndrome (MFS; MIM 154700) is one of the most frequent genetic diseases with a prevalence of 1 in 5,000 Europeans [2]. It is inherited as an autosomal dominant trait with complete penetrance but with phenotypic expression that varies considerably, both between and within families. Affected individuals develop varying patterns of organ involvement including the cardiovascular, ocular, skeletal, and pulmonary systems, the skin, and the dura [3]. Typical complications include severe scoliosis or 
pectus excavatum, spontaneous pneumothorax, retinal detachment, or sight-threatening glaucoma resulting from dislocated lenses. Undiagnosed Marfan patients usually die from acute aortic dissection or rupture and thus have an average life expectancy of only 32 years [4]. Early diagnosis and initiation of management by expert centers, on the other hand, extends the life expectancy of Marfan patients to over 60 years of age [3].

We want to present the sudden death of a young man with previously undiagnosed MFS and an autopsy was carried out because of suspected medical malpractice. Although that suspicion was rapidly rejected, the diagnosis of MFS had major consequences for the relatives of the deceased.

\section{Case}

A 31-year-old man experienced sudden massive pain in the chest and abdomen. He was taken to the emergency room of a hospital and died shortly after arrival. As no diagnosis was established, the physicians stated an unknown cause and manner of death. The district attorney had a medicolegal autopsy performed as medical malpractice was suspected.

\section{Findings at autopsy}

The deceased was of high build $(1.88 \mathrm{~m})$, with pectus excavatus, peculiarly long legs and arms, and noted arachnodactyly.

Internally, the aortic root was grossly enlarged and $1 \mathrm{~cm}$ distal from the aortic valve a longitudinal rupture of the internal layer of the aorta was found (Fig. 1). The aortic

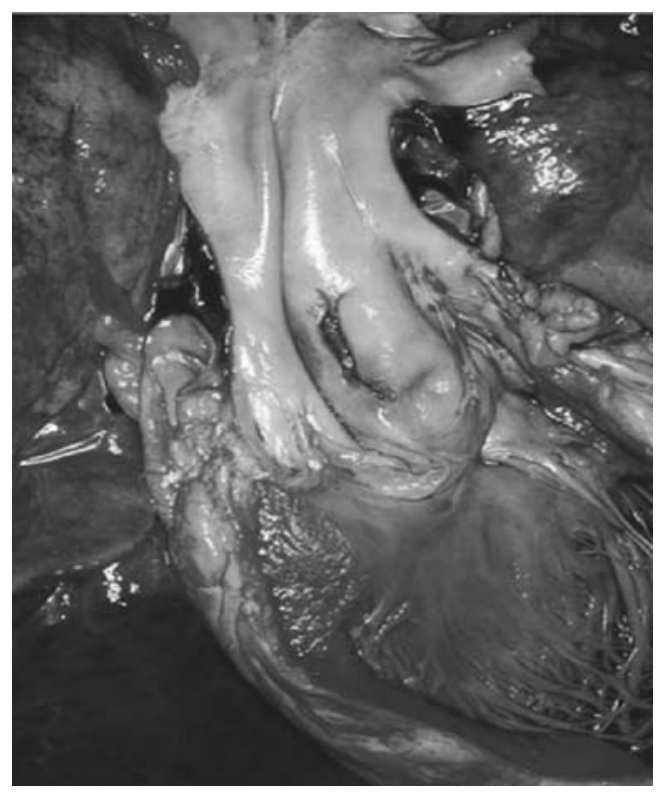

Fig. 1 Longitudinal rupture of the extended aortic root

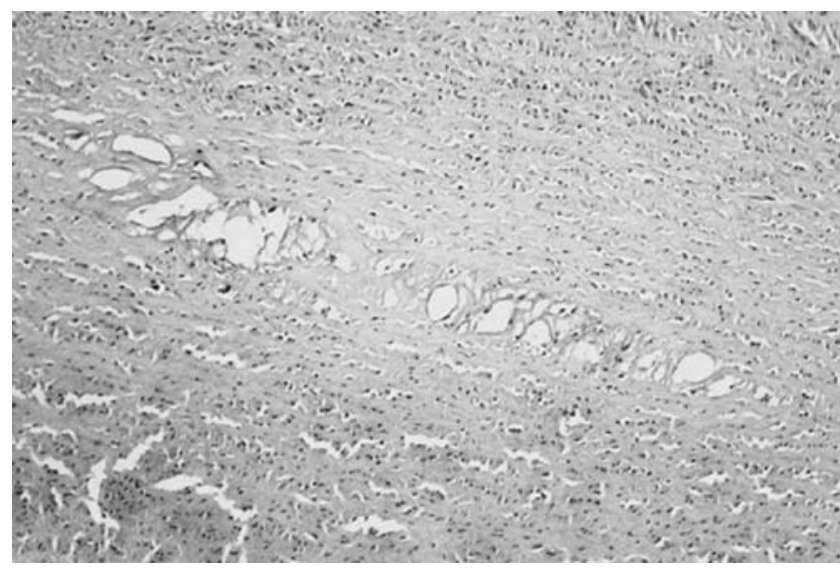

Fig. 2 Hematoxylin eosin staining of the media of the aorta showing pseudocysts with deposition of mucoid substances

wall showed a dissection and bleeding into the wall of nearly the whole vessel, and the blood had found its way via the wall of the right coronary artery and through the epicardium into the pericardial sack that contained 250-ml partly coagulated blood.

In hematoxylin-eosin staining (Fig. 2), the aorta showed pseudocystic changes in the muscular layer, with deposition of mucoid substances that stained blue in alcian blue stain (not shown). In the Elastica van Giesson stain, the aortic root showed extension and loss of elastic fibers (Fig. 3). The histologic picture was thus that of a pseudocystic medionecrosis.

Further information from the relatives of the deceased

Shortly after the autopsy, the sister and the pregnant fiancé of the deceased asked for the cause of death. They expressed severe concerns that he might have died from a heritable disease, as his father also died suddenly at an age of 31 years. An autopsy had been performed on the father at the pathologic department of another hospital. We were able to

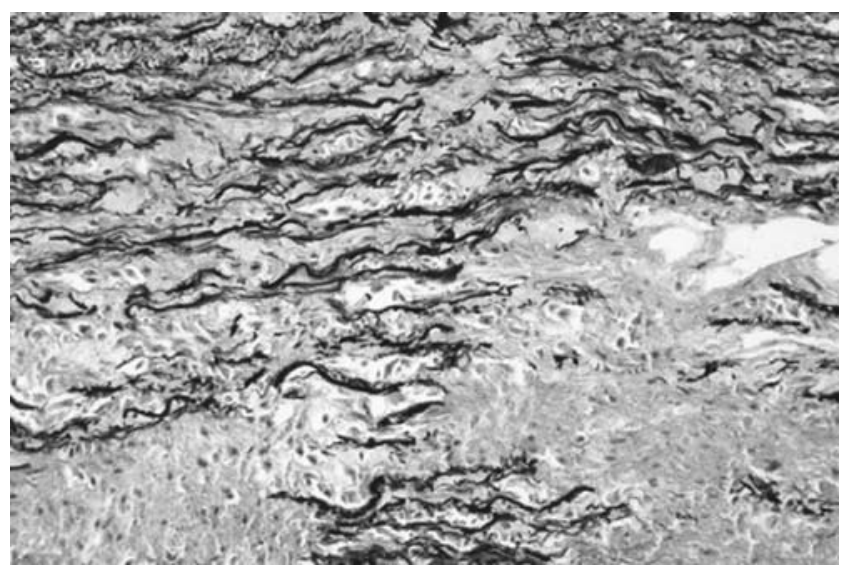

Fig. 3 Elastica van Giesson staining of the aortic root showing extension and loss of elastic fibers 
obtain the autopsy protocol and found that he had also died from aortic rupture. Macroscopic and histologic findings were nearly identical. Thus, we told the relatives that we assumed that both the deceased and his father had suffered from MFS and that the probability of transmission to either sister or an unborn child is $50 \%$. To further investigate this suspicion, we recommended genetic testing of the deceased, his sister, and daughter who was born soon afterwards.

\section{Genetic testing}

With the consent of the relatives of the deceased, mutation screening was performed in the deceased, his sister, and the daughter by use of direct sequencing of genomic DNA of the fibrillin-1 gene (FBN1) from peripheral blood samples. While the daughter showed the consensus wild-type sequence, a point mutation at position 1622 was found in both the deceased and his sister, with exchange of guanine against adenine $(1622 \mathrm{G}>\mathrm{A})$. This mutation causes the exchange of the amino acid cysteine to tyrosine at position 541 of fibrillin-1 (Cys541Tyr).

At the time of the investigation, this mutation had not previously been reported but it was later published by Rommel et al. [5].

\section{Discussion}

A traumatic aortic rupture in young years and without atherosclerotic changes is always suspicious for genetic disorders. Examples would be Ehlers-Danlos disease type IV or the Loeys-Dietz syndrome [6, 7], but the most common of these disorders is MFS [3].

About $85 \%$ of all cases of MFS are caused by one of more than 600 known different mutations in FBN1, whereas mutations in the transforming growth factor- $\beta$ receptor 2 (TGF- $\beta \mathrm{R} 2$ ) gene are rarely observed [5-9]. As this protein is of importance in the formation of elastic fibers, the general pathogenetic principle of this disease is the diminished resistance of all tissues and organs to traction and pressure [10]. The spectrum of symptoms varies broadly: The major findings that can (but not necessarily must) be observed in this disease and that can also be identified during an autopsy are elongated bones, especially fingers and metacarpals, but also deformations of the thorax or the palate, mandible, and maxilla. These skeletal findings are explained by a decreased resistance of the periosteum to stretching that results in accelerated length growth of the bones [3]. Other findings, explained by a similar mechanism, are emphysema, hyperflexibility of the joints, and luxations of the lens. Crucial for the life expectancy, however, is the enlargement of large arteries, most notably the aortic root that in most cases leads to death from aortic rupture, typically in aortic roots of more than $6 \mathrm{~cm}$ in diameter. Prophylactic therapy with beta-blockers (as early as possible) and aortic root graft surgery in patients with aortic root diameters of more than $6 \mathrm{~cm}$ can double the life expectancy [3].

Unfortunately, phenotypic variation appears to be largely independent of the type of mutation. Thus, in some cases, persons with mutations will have a normal life expectancy, while in other cases persons with marfanoid habitus will have a normal FBN1 gene and sometimes even a normal $T G F-\beta R 2$ gene [11]. Moreover, the rate of sporadic cases (de novo mutations) is estimated at $25 \%$. Another problem is that the diagnosis of MFS is tedious: As there is such a diversity of mutations, on top of sequencing 65 exons of the $F B N 1$, gene analysis of the $T G F-\beta R 2$ gene may be required. These pitfalls make the MFS a diagnostic challenge both for the pathologist and the human geneticist [2].

In our case, the deceased showed typical arachnodactyly and tall build ("marfanoid habitus"), pectus excavatus, and a longitudinal rupture of the extended aortic root. These findings and the fact that the father of the deceased had also died from aortic root rupture at a similar age made the presence of MFS probable, but it must be borne in mind that a substantial proportion of patients with this syndrome can present with aortic rupture but only slight extra-arterial symptoms [2, 3].

Thus, MFS has to be distinguished from idiopathic cystic medial necrosis (Erdheim-Gsell syndrome, Erdheim disease) [12-14], a poorly delimited syndrome that shows the same histologic findings as in MFS but lacks extravascular findings. Both for Erdheim-Gsell syndrome and for MFS, only a small number of reports of sudden deaths exists in the forensic literature [15-18]. There is some argument whether Erdheim-Gsell syndrome exists as such [19]. It is discussed to be only an exaggerated age-related change or a manifestation of several diseases that cannot be distinguished by a routine autopsy, the most important most probably MFS [20]. This discussion is further nurtured by the recently found high incidence of atypical Marfan syndromes without the "typical marfanoid habitus," but with mutations of FBN1 [21]. Thus, we feel that the experience from our case should prompt pathologists to use the diagnosis "Erdheim-Gsell Syndrome" as rarely as possible and take advantage of genetic testing for MFS in all cases with juvenile cystic medionecrosis, even without the presence of a "marfanoid habitus." The goal of this procedure should be not only to establish the correct diagnosis but also to give relatives, as in our case, the opportunity of early prophylactic treatment. But not only we forensic pathologists are challenged, also the attorneys that (in the eyes of the authors) should have an autopsy ordered in every case of sudden death without prior known diseases up to the third decade, as both death from heritable 
diseases often occurs suddenly and unexpected in young years without prior diagnosis [22-24], and the chance of a neglected unnatural death is much higher in sudden deaths in younger years than afterwards [25].

Open Access This article is distributed under the terms of the Creative Commons Attribution Noncommercial License which permits any noncommercial use, distribution, and reproduction in any medium, provided the original author(s) and source are credited.

\section{References}

1. Brinkmann B, Du Chesne A, Vennemann B (2002) A survey of autopsy rates in Germany. Dtsch Med Wochenschr 127:791-795

2. von Kodolitsch Y, Robinson PN (2007) Marfan syndrome: an update of genetics, medical and surgical management. Heart 93:755-760

3. Judge DP, Dietz HC (2005) Marfan's syndrome. Lancet 366: 1965-1976

4. Silverman DI, Burton KJ, Gray J et al (1995) Life expectancy in the Marfan syndrome. Am J Cardiol 75:157-160

5. Rommel K, Karck M, Haverich A et al (2005) Identification of 29 novel and nine recurrent fibrillin-1 (FBN1) mutations and genotype-phenotype correlations in 76 patients with Marfan syndrome. Hum Mutat 26:529-539

6. Germain DP (2007) Ehlers-Danlos syndrome type IV. Orphanet J Rare Dis $2: 32$

7. Banaschak S, Driever F, Nerlich A, Madea B (2002) Aortenruptur bei einem 18-jährigen Mann. Postmortale Diagnose eines EhlersDanlos-Syndroms Typ IV. Rechtsmedizin 12:153-158

8. Kumar Singh K, Elligsen D, Liersch R, Schubert S, Pabst B, Arslan-Kirchner M, Schmidtke J (2007) Multi-exon out of frame deletion of the FBN1 gene leading to a severe juvenile onset cardiovascular phenotype in Marfan syndrome. J Mol Cell Card 42:352-356

9. Boileau C, Jondeau G, Mizuguchi T, Matsumoto N (2005) Molecular genetics of Marfan syndrome. Curr Opin Cardiol 20:194-200

10. Robinson PN, Booms P (2001) The molecular pathogenesis of the Marfan syndrome. Cell Mol Life Sci 58:1698-1707
11. Hirani R, Koszyca B, Byard RW (2008) Marfan syndrome and sudden death within a family - aetiologic, molecular and diagnostic issues at autopsy. J Forensic Legal Med 15:205-209

12. Erdheim J (1929) Medionecrosis aortae idiopathica. Virchows Arch A Pathol Anat Histopathol 273:454-479

13. Erdheim J (1930) Medionecrosis aortae idiopathica cystica. Virchows Arch A Pathol Anat Histopathol 276:187-229

14. Gsell O (1928) Wandnekrosen der Aorta als selbständige Erkrankung und ihre Beziehung zur Spontanruptur. Virchows Arch A Pathol Anat Histopathol 270:1-36

15. Dettmeyer R, Schmidt P, Madea B (1998) Two cases of unexpected sudden death due to cystic medionecrosis of the aorta associated with bloodless aortic dissection. Forensic Sci Int 94:161-166

16. Vock R, Schulz E (1986) Marfan syndrome. A case report. Z Rechtsmed 96:67-78

17. Schmidt P, Madea B, Oehmichen M, Gerling I (1996) Plötzlicher Tod bei idiopathischer cystischer Medianekrose-Analyse von 6 Fallen unter Berücksichtigung arztrechtlicher Fragen. Rechtsmedizin 6:39-44

18. Byard RW (2006) Sudden death in Marfan syndrome. In: Tsokos M (ed) Forensic pathology reviews, vol. 4. Humana, Totowa, pp 93-106

19. Trotter SE, Olsen EG (1991) Marfan's disease and Erdheim's cystic medionecrosis. A study of their pathology. Eur Heart J 12:83-87

20. Hirst AE Jr, Johns VJ Jr, Kime SW Jr (1958) Dissecting aneurysm of the aorta: a review of 505 cases. Medicine (Baltimore) 37 (3):217-279

21. Palz M, Tiecke F, Booms P et al (2000) Clustering of mutations associated with mild Marfan-like phenotypes in the $3^{\prime}$ region of FBN1 suggests a potential genotype-phenotype correlation. Am J Med Genet 91:212-221

22. Klintschar M, Stiller D (2004) Sudden cardiac death in hereditary hemochromatosis: an underestimated cause of death? Int J Legal Med 118:174-177

23. Wedekind H, Bajanowski T, Friederich P et al (2006) Sudden infant death syndrome and long QT syndrome: an epidemiological and genetic study. Int J Legal Med 120:129-137

24. Heide S, Romanowski U, Kleiber M (1999) Postmortale Lipoproteinbestimmung bei juveniler Koronararteriensklerose. Rechtsmedizin 9:197-200

25. Madea B (2007) Praxis Rechtsmedizin. Springer Medizin, Heidelberg 